\title{
Synthesis and characterization of CdS and CdSe nanoparticles prepared from novel intramolecularly stabilized single-source precursors
}

\author{
KARUPPASAMY KANDASAMY ${ }^{\mathrm{a}}$, HARKESH B SINGH ${ }^{\mathrm{a}}$ and \\ SHAILENDRA K KULSHRESHTHA ${ }^{\mathrm{b}}$ \\ ${ }^{a}$ Department of Chemistry, Indian Institute of Technology Bombay, Powai, Mumbai 400076 \\ ${ }^{b}$ Novel Materials and Structural Chemistry Division, Bhabha Atomic Research Center, Mumbai 400085 \\ e-mail: chhbsia $a$ chem.iitb.ac.in
}

MS received 2 November 2008; revised 28 January 2009

\begin{abstract}
In this note we describe the synthesis of cadmium sulphide and selenide nanoparticles from the corresponding novel single source precursors, $M[E(O x)]_{2}[E=S(1)$, Se (2); $M=C d ; O x=2-(4,4-$ dimethyl-2-oxazolinyl)benzene] by thermolysing in tri- $n$-octylphosphine oxide (TOPO) at $280{ }^{\circ} \mathrm{C}$, and their characterization by X-ray powder diffraction (XRD), transmission electron microscope (TEM) and scanning electron microscope (SEM) studies.
\end{abstract}

Keywords. Nanoparticle; CdSe; CdS; TEM; XRD; SEM; hexagonal phase.

\section{Introduction}

Much recent interest has been directed towards the preparation of group 12-16 semiconductors using group 12 metal chalcogenolates as single-source precursors. ${ }^{1}$ The intermediate energy band gaps of these semiconductors have led to their use in a variety of devices. ${ }^{2}$ In recent years the group 12 metal chalcogenolates and related precursors have been used for the preparation of high quality nanoparticles. ${ }^{3}$ Recently, our group has reported the synthesis of monomeric group 12 metal thiolates ${ }^{4}$ and selenolates ${ }^{5}$ using ligands containing intramolecularly coordinating nitrogen donor atom. In this note, we demonstrate the synthesis and characterization of cadmium sulfide and selenide nanoparticles from the corresponding single source precursors, cadmium thiolate (1) and selenolate (2) derivatives.

\section{Experimental}

\subsection{Materials and methods}

All reactions were carried out under inert atmosphere using nitrogen or argon with standard vac-

*For correspondence uum-line techniques. All solvents were purified by standard procedures ${ }^{6}$ and freshly distilled prior to use. Cadmium thiolate $(\mathbf{1})^{4}$ and selenolate $(2)^{5 a}$ derivatives were prepared by reported methods. Commercially available tri- $n$-octylphosphine (TOP) and tri- $n$-octylphosphine oxide (TOPO) were used as received. Powder X-ray diffraction patterns were recorded using $\mathrm{Ni}$ filtered $\mathrm{Cu}-\mathrm{K} \alpha$ radiation $(\lambda=1.5418 \AA)$ with a Philips PW1820 X-ray diffractometer. SEM photographs were taken on a JEOL JSM330A instrument. For TEM studies, a suspension of the sample powder in acetone was prepared using ultrasonification and a small drop of it was put on the porous carbon grid and allowed to dry. The micrographs were taken with a JEOL2000FX machine operating at $160 \mathrm{kV}$.

\subsection{Synthesis of CdS and CdSe nanoparticles}

Tri- $n$-octylphosphine oxide (TOPO) was dried and degassed by heating to about $100^{\circ} \mathrm{C}$. The temperature was then stabilized at $280^{\circ} \mathrm{C}$ under inert atmosphere. $\mathrm{Cd}\left[\mathrm{S}(\mathrm{Ox}]_{2}(1)(0.52 \mathrm{~g}, 1 \mathrm{mmol})\right.$ dispersed in $15 \mathrm{~cm}^{3}$ of tri- $n$-octylphosphine (TOP) was rapidly injected into the hot TOPO $(20 \mathrm{~g})$ at $280^{\circ} \mathrm{C}$. After sudden fall in temperature to $240^{\circ} \mathrm{C}$ the temperature was stabilized at $280^{\circ} \mathrm{C}$ and continued for $30 \mathrm{~min}$. 




Figure 1. (a) Powder X-ray diffraction patterns of (a) CdSe and (b) CdS. Inset in (a) shows the electron diffraction pattern for CdSe.

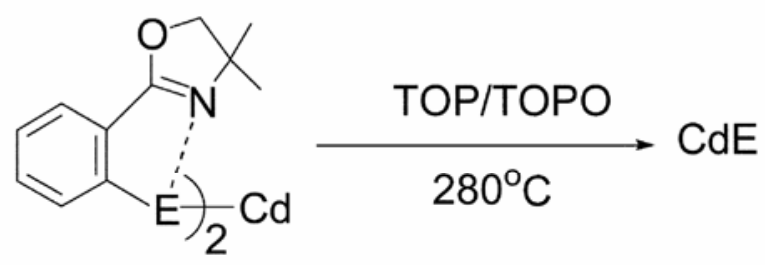

$1 \mathrm{E}=\mathrm{S}, 2 \mathrm{E}=\mathrm{Se}$

Scheme 1.

After cooling to $70^{\circ} \mathrm{C}$ an excess of methanol was added to give a flocculent precipitate. The solid was separated by centrifugation and the precipitate was washed several times with methanol to remove the excess TOPO. The precipitate was evaporated under vacuum to get cadmium sulphide nanoparticles.

Cadmium selenide nanoparticles were similarly prepared from $\mathrm{Cd}[\mathrm{Se}(\mathrm{Ox})]_{2}(2)(0.61 \mathrm{~g}, 1 \mathrm{mmol})$.

\section{Results and discussion}

$\mathrm{CdS}$ and $\mathrm{CdSe}$ nanoparticles were prepared by thermolysing the corresponding single source precur- sors, cadmium thiolate $(\mathbf{1})^{4}$ or selenolate $(2)^{5 a}$ in TOPO at $280{ }^{\circ} \mathrm{C}$ (scheme 1) by following a reported procedure with slight modification ${ }^{7}$. The yellow $(\mathrm{CdS})$ and black $(\mathrm{CdSe})$ precipitates obtained after the completion of reaction were characterized by various techniques to investigate their particle size and structural features.

Figures 1(a) and (b) show the powder X-ray diffraction patterns of $\mathrm{CdSe}$ and $\mathrm{CdS}$, respectively which are characteristic of the hexagonal phase of these samples. The analysis of $\mathrm{CdSe}$ data gave a value of ' $a$ ' $=4.291$ and ' $c$ ' $=7.015 \AA$ and the corresponding values for $\mathrm{CdS}$ are 4.124 and $6.686 \AA$ which are in agreement with the values reported in the literature (table 1). ${ }^{8}$ The selective area electron diffraction pattern (SAED) for CdSe exhibits broad diffused rings that are typical of nano-sized particles and a representative pattern is shown in figure 1 (a) as an inset, which is consistent with the XRD results. The TEM image for CdSe nanoparticles is shown in figure 2. The TEM micrograph shows well-defined nanoparticles having a diameter of about $200 \mathrm{~nm}$. The surface morphology of CdSe was studied by SEM (figure 3) technique that shows that 
Table 1. Powder X-ray diffraction data of CdSe and CdS.

\begin{tabular}{lllcc}
\hline Crystalline phase & $2 \theta$ (observed) & $2 \theta$ (reference) & Lattice parameters $(\AA)$ (observed) & Lattice parameters $(\AA)^{8}$ \\
\hline CdSe & $23.89(100)$ & $23.88(100)$ & $a=4.291$ and & $a=4.299$ and \\
& $25.39(002)$ & $25.39(002)$ & $c=7.015$ & $c=7.010$ \\
& $27.09(101)$ & $27.09(101)$ & & \\
& $41.99(110)$ & $41.99(110)$ & & \\
& $45.81(103)$ & $45.81(103)$ & & \\
& $49.73(112)$ & $49.72(112)$ & & $a=4.121$ and \\
CdS & $24.91(100)$ & $24.93(100)$ & $a=4.124$ and & \\
& $26.67(002)$ & $26.66(002)$ & $c=6.686$ & \\
& $28.31(101)$ & $28.33(101)$ & & \\
& $43.91(110)$ & $43.91(110)$ & & \\
& $58 \cdot 11(103)$ & $48.12(103)$ & & \\
& $52.11(112)$ & $52.11(112)$ & & \\
\hline
\end{tabular}

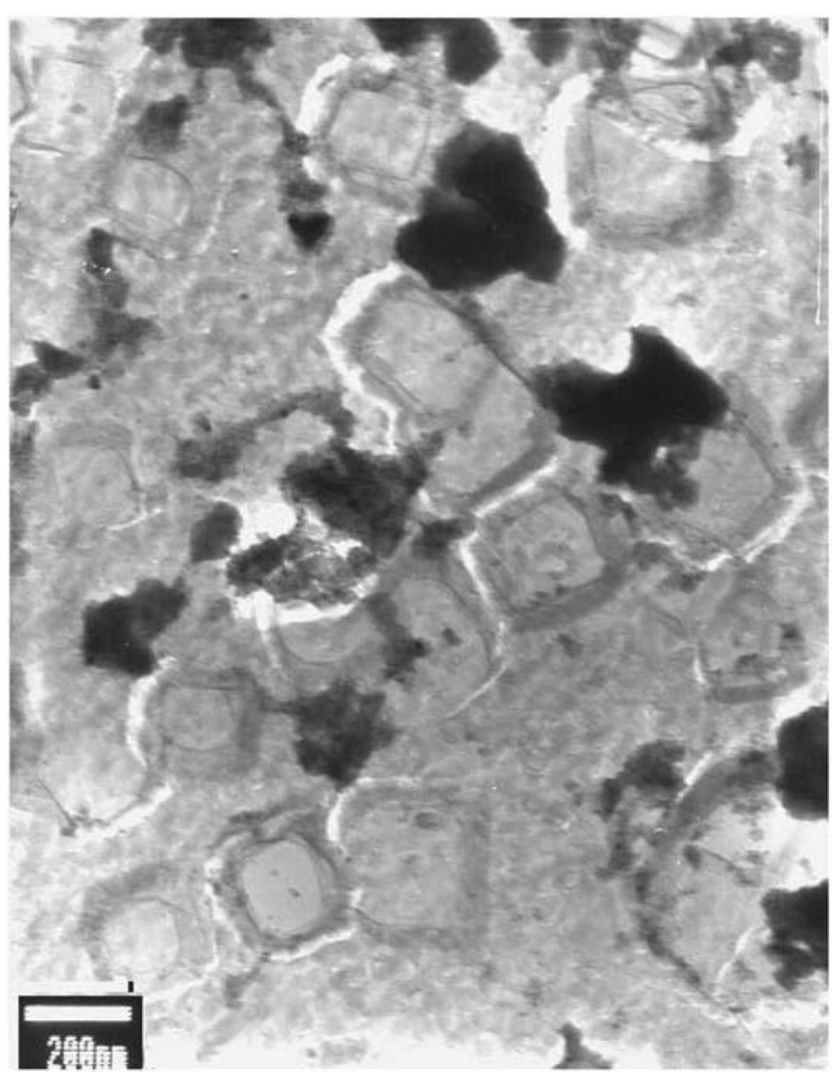

Figure 2. TEM photograph of CdSe.

these materials are polycrystalline in nature. Particle sizes are found to be 3-4 microns. The particle size is much bigger than that of crystallite size measured by TEM analysis. This may be due to the agglomeration of crystallites which is clearly seen from the figure 3 .

\section{Conclusion}

The preparation of cadmium sulphide and cadmium selenide nanoparticles from intramolecularly stabi-

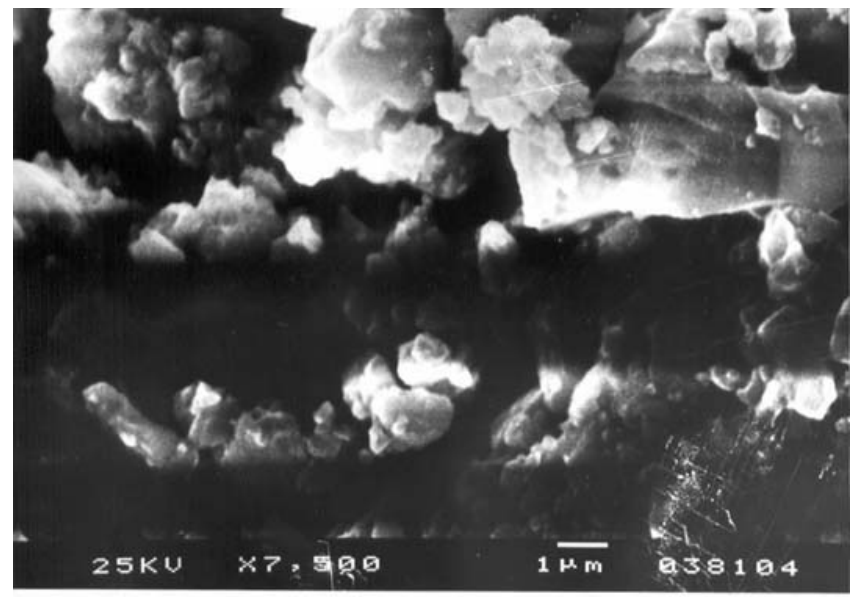

Figure 3. SEM photograph of CdSe.

lized cadmium chalcogenolate single source precursors has been demonstrated. The above results suggest that the metal chalcogenolates stabilized by intramolecular coordination can be used for the preparation of respective metal chalcogenide nanoparticles by thermolysis method.

\section{Acknowledgements}

We are grateful to Board of Research in Nuclear Sciences (BRNS) and Council of Scientific and Industrial Research (CSIR) for grants.

\section{References}

1. (a) Arnold J 1995 Prog. Inorg. Chem. 43 353; (b) Gleizesb A N 2000 Chem. Vap. Deposition 6 155; (c) Bochmann M 1996 Chem. Vap. Deposition 285 and references therein

2. O'Brien P and Nomura R J 1995 Mater. Chem. 51761 and references therein 
3. (a) Ludolph B, Malik, M A, O'Brien P and Revaprasadu N 1998 Chem. Commun. 1849; (b) Crouch D J, O'Brien P, Malik M A, Skabara P J and Wright S P 2003 Chem. Commun. 1454; (c) Revaprasadu N, Malik M A, O'Brien P and Wakefield G 1999 Chem. Commun. 1573; (d) Afzal M, Malik M A and O'Brien P 2004 Chem. Commun. 334; (e) Kedarnath G, Kumbhare L B, Jain V K, Phadnis P P and Nethaji M 2006 Dalton Trans. 2714; (f) Kedarnath G, Jain V K, Ghoshal S, Dey G K, Ellis C A and Tiekink E R T 2007 Eur. J. Inorg. Chem. 1566; (g) Kedarnath G, Dey S, Jain V K, Dey G K and Varghese B 2006 Polyhedron 252383
4. Mugesh G, Singh H B and Butcher R J 1999 Eur. J. Inorg. Chem. 1229

5. (a) Mugesh G, Singh H B, Patel R P and Butcher R J 1998 Inorg. Chem. 37 2663; (b) Kaur R, Singh H B, Patel R P and Kulshreshtha S K 1996 J. Chem. Soc., Dalton Trans. 461

6. Perrin D D, Armargo W L F and Perrin D R 1980 In Purification of laboratory chemicals (New York: Pergamon)

7. (a) Trindade T and O'Brien P 1996 Adv. Mater. 8 161; (b) Trindade T and O'Brien P 1997 Chem. Mater. 9523

8. PDF-2, database 1990 JCPDS-International center for diffraction data, 80-0006 and 77-2307 